\title{
Reversible Male Contraceptives Preferences in Nigeria Survey
}

\author{
Francis Eremutha*,Veronica Chizoba Gabriel
}

Women Friendly Initiative, Kuje Area Council, Abuja FCT, Nigeria

Copyright $\mathrm{C} 2018$ by authors, all rights reserved. Authors agree that this article remains permanently open access under the terms of the Creative Commons Attribution License 4.0 International License

\begin{abstract}
Male contraceptive preferences in Nigeria are major pointers to acceptance, demand and sustained use of new reversible male contraceptive technologies. This study is designed to assess the willingness of Nigerian men to become actors in shared reproductive responsibility. A cross-sectional study design with mixed-methodology, which adopted both qualitative and quantitative research using desk research, in-depth and household interviews, focus group discussions and online polls - was adopted. A total of 1,442 respondents were questioned; 801 from rural areas and 641 from urban areas. Male contraceptive use was defined by factors that influence the desire to practice contraception. $68.85 \%$ of the respondents say they would use reversible male contraceptives, if they were available; $54.27 \%$ of the respondents who were against it, said they would not use reversible male contraceptives because of the fear of adverse health risks. Our findings show that a considerable proportion of men had knowledge of family planning methods. The results show that there is a demand for reversible male contraceptives among the male population in Nigeria. It is evident that if other types of reversible male contraceptives are made available, they will be readily accepted.
\end{abstract}

Keywords Reversible Male Contraceptives, Male Contraceptive Preferences

\section{Introduction}

Contraception also known as birth control and fertility control is a method or device used to prevent pregnancy, [1]. The use of contraception dates to ancient times. However, the use of safe and effective methods only became available in the 20th century. The process of planning, making available and using birth control is called family planning. Some cultures limit or discourage access to birth control because they consider it to be morally, religiously, or politically undesirable [2]. Globally contraceptives are used by the majority of married or in-union women in almost all regions. As of 2015, 64 per cent of married or in-union women of reproductive age worldwide were using some form of contraception. However, contraceptive use was much lower in the least developed countries (40 per cent) and was particularly low in Africa (33 per cent). Among the other major geographic areas, contraceptive use was much higher, ranging from 59 per cent in Oceania to 75 per cent in Northern America. Within these major areas there are significant differences by region and across countries [3].

Modern contraceptive methods constitute most contraceptive use. Globally in 2015,57 per cent of married or in-union women of reproductive age used a modern method of family planning, constituting 90 per cent of contraceptive users. When users of traditional methods are counted as having an unmet need for family planning, 18 per cent of married or in-union women worldwide are estimated to have had an unmet need for modern methods in 2015[4].

Africa has the lowest percentage of women using contraceptives, and the highest unmet need in the world. Despite that, some African countries have made the biggest leaps in contraception use over the past years and are projected to make the greatest gains in the years to come [3]. In Nigeria, The Federal Government's advocacy on the use of contraceptive among sexually active women in Nigeria for the prevention of unwanted pregnancy and abortion is beginning to yield positive results as more women are recorded to be embracing the method. Compiled data from the 2015 report of the National Bureau of Statistics, NBS, on health shows that contraceptive use among sexually active women of child bearing age increased by seven per cent compared to 2014 [4].

The most effective methods of birth control are the irreversible methods know as sterilization by means of vasectomy in males and tubal ligation in females. There are also intrauterine devices (IUDs), and implantable birth control. This is followed by many hormone-based methods including oral pills, patches, vaginal rings, and injections. Less effective methods include physical 
barriers such as condoms, diaphragms and birth control sponges and fertility awareness methods. The least effective methods are spermicides and withdrawal by the male before ejaculation. There is also emergency birth control which can prevent pregnancy if taken within 72 to 120 hours after unprotected sex. Although female contraceptives are very effective at preventing unintended pregnancy, some women cannot use them because of health conditions or side-effects, leaving some couples without effective contraceptive options. In addition, many men wish to take active responsibility for family planning. Thus, there is a great need for male contraceptives to prevent unintended pregnancies, of which $80-90$ million occur annually.

Male contraception began with the use of the condom and dates to ancient times in Imperial Rome and ancient Egypt although there isn't any concrete evidence to back this claim. The condoms or sheaths are the oldest form of barrier contraception used by the male [5].

Today the condom is still in use and is one of only two methods available to men, aside from early withdrawal, which is always problematic. Vasectomy for contraception, the second method available, is a more recent invention that was initially for criminals and other degenerates. Today these two methods persist; men still have two choices for contraception, the condom and vasectomy.

The responsibility of fertility regulation tilts significantly to the women and isn't shared equally with men, this is a Global fact. While there have been a variety of efforts and available options for contraception directed exclusively at the women the lack of male involvement may strongly reflect the limitations such as Options and orientation. Available options are either coitus dependent or restricted irreversible vasectomy. New male methods, particularly if reversible, may alter men's willingness to accept or share responsibility for the control of fertility [2].

Access to effective contraception is a prerequisite of reproductive health If at all the goal of ensuring that every birth results from a planned pregnancy is to be achieved. To achieve this, a wider range of methods of regulating fertility must be available to accommodate both genders. Perhaps the reason is that women are left "holding the baby," literally, family-planning organizations have traditionally concentrated on female methods [6]. Decades ago, the biological basis for male contraception was established. However, despite promising breakthroughs and the financial burden men increasingly bear due to better enforcement of child support policies, no viable alternative to the condom has been brought to market. Men who wish to control their fertility must rely on female compliance with contraceptives, barrier methods, vasectomy or abstinence [6].

Research work on male contraception began with a search for easy targets specific to the male aiming to disrupt sperm or testis function. In the context of the success of the female "pill" the most obvious choice was a hormonal approach in which testosterone or its analogues were used to inhibit testicular steroidogenesis to block spermatogenesis. Non-hormonal targets for contraception however, were not obvious and much more difficult to define $^{3}$. New contraceptive technologies, especially effective male contraceptives if made available are likely to be widely used and accepted and would dramatically change the way in which contraception is provided around the world.

\subsection{Willingness to Use Male Contraceptives}

Male willingness to use a novel male method has been studied through various survey studies, as have female attitudes toward male contraception however most surveys measure only hypothetical behaviours. These hypothetical behaviours serve as a gauge across various groups and provide important perspective. Culture plays a very key role in influencing perception and belief, a cross-cultural study carried out to assess attitudes toward hormonal male contraception interviewed a total of 1843 man across the globe from Europe in Edinburgh to Cape Town in Africa, Shanghai and Hong Kong in Asia, the results showed that majority of participants would use a male contraceptive pill if available [7]. Survey data of women's attitudes also show support for male contraceptive methods. In a survey of women in Edinburgh, Cape Town, Shanghai and Hong Kong, more than $70 \%$ of all women and over $90 \%$ of women in South Africa and Scotland, thought that a 'male pill' was a promising idea and $65 \%$ of women overall felt that the responsibility of contraception fell too heavily upon women. In Hong Kong and Shanghai, of the women who were negative or unsure about male contraception, the primary concern was health risks. In Scotland and South Africa, women were more likely to attribute their negative attitudes to a reluctance to rely on their partner. However, only $2 \%$ of women overall indicated that they would not trust their partner to use contraception. These data indicate that while women may not trust men in general to take the pill, they were more trusting when it came to their own partner [7].

In another survey of over 9000 men aged 18-50 years from nine countries, $28.5-71.4 \%$ of various nationalities expressed willingness to use a hormonal male contraceptive, with an overall willingness rate of $55 \%$, while $55-81.5 \%$ of these participants indicated that both they and their partner participate in the selection of a contraceptive method already. Even more positive figures were reported in a study of Australian men's attitudes toward male contraception in which $75.4 \%$ of new fathers interviewed indicated they would be willing to try a male method if it were available [8].

These surveys shed light on the role of cultural differences in acceptability for example predominantly 
Muslim communities in Indonesia were less willing to use male contraceptives, citing religious beliefs and Australian migrants were less receptive than those born in Australia. However, even in Indonesia where willingness was lowest, a quarter of the population surveyed $(28.5 \%)$ responded positively [9]. In a UK survey of 134 female and 54 male users of contraceptives, acceptability of a 'male pill' was $49.5 \%$. Forty-two percent of respondents expressed concerns that men would forget to take a male pill, women being much more likely to express this concern than men, contrasting with the $2 \%$ of women in the study [7]. Those who were unwilling or undecided about the pill were likely to express concerns about the effect of a pill on future fertility [10]. Another smaller survey looking a group of youths, 30 young African American men and women. Overall, $67 \%$ of males and females had positive impressions of male hormonal contraception. A large majority (85\%) of females indicated they would trust their partners to use the method and most males $(60 \%)$ indicated intentions to use the product were it available [11].

Although Survey data is very likely to overestimate the population of potential users of male contraception. Note that the lowest expressions of interest in male contraception from these surveys are many times the usage rates for most current, 'successful' female birth control methods so much that even assuming that only $25 \%$ of men who indicated they would be willing (Definitely or Probably) use male contraception in the survey [12], the estimated number of potential users aged 15-64 years in those nine countries alone is close to 44 million [6].

\section{Methodology}

A cross-sectional study design with mixed-methodology which adopted both qualitative and quantitative research methodologies was carried out in 3 states chosen across three of six geopolitical zones of Nigeria: FCT Abuja, Lagos State and Kano State. In each of the 2 states, 6 local government areas were randomly selected per senatorial district and in Abuja, all 6 area councils were sampled. Therefore, a total of 12 LGAs and 6 area councils were recruited for the survey.
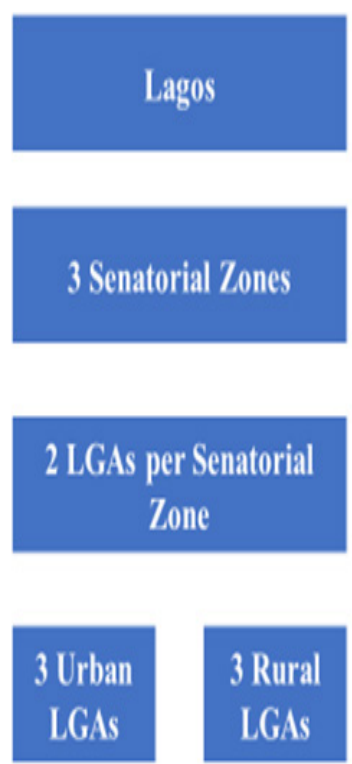
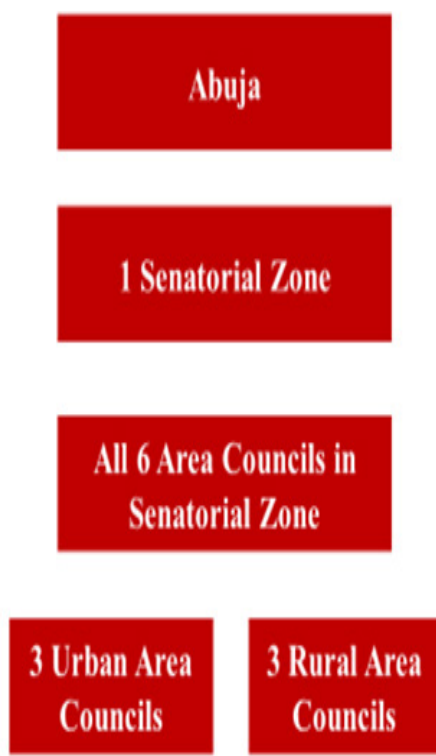
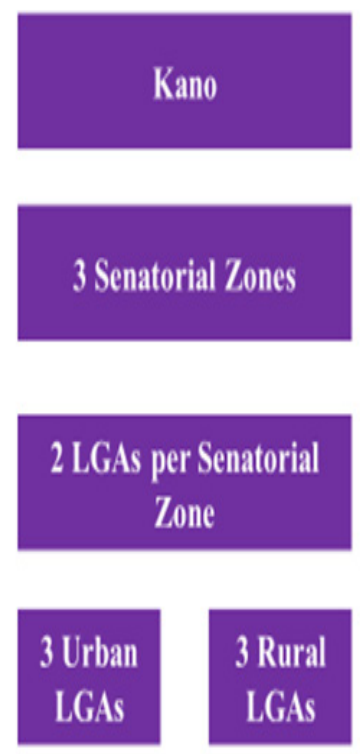

\section{Households}

Figure 1. Chart Showing Survey Locations 
An in-depth review was conducted to comprehensively analyze existing studies, data, publications, and reports on male use of contraceptive in Nigeria and wiliness to use modern technologies if made available around the world. The appropriate data sources such as published studies, research and survey reports and relevant grey literatures were reviewed. In-depth interviews (IDIs) with key stakeholders at the State, LGA, CBO, and community levels were conducted. An interview guide with open-ended questions was developed to further explore information from all respondents. Respondents for this survey were male community members aged 16-65 years who are residents of Abuja, Lagos and Kano States. Focus Group Discussions (FGDs) which allowed participants to discuss topical issues in detail, helping them explore and clarify their points of view, thus enhancing in-depth discussions, were carried out. This mainly involved community members. The sessions enabled exploratory and confirmatory questions to be asked from participants for them to achieve deeper understanding on their interests and needs. To achieve this, ensured homogeneity of participant groups that captured the key attributes of the target population was ensured. The groups were constituted in ways that did not hamper the discussion of sensitive topics due to differences in age, occupation, lifestyle, roles and status in the community. Manageable group sizes with the aim of achieving saturation of the responses were maintained. The research team also conducted structured community-based household surveys in selected LGAs. The objective was to select representative sample households in each of the LGAs and area councils selected to represent fully both rural and urban perceptions of the subject matter. A single question poll was also administered on the Twitter handle of Nigeria Health Watch (EpiAFRIC's sister organisation).

Variables used for analyses were classified into the following categories:

- $\quad$ "Socio demographic characteristics" including age (years), education level (no formal education, primary, secondary, vocational, university, post-graduate), occupation (Artisan, Businessman, Civil Servant, Trader, Farmer, Religious Leader, etc.) and relationship status (married, engaged, in a relationship, etc.).

- Respondent's knowledge of available contraceptives
- Respondent's knowledge of reversible and non-reversible contraceptives available to male and female.

- Respondent's use of contraceptives and reasons of use.

- Respondent's willingness to use other forms of reversible male contraceptives and reasons why or why not.

Questionnaires for the quantitative interviews were administered to a total of 1,442 respondents: $55.55 \%$ of the respondents (801) were from rural areas; $45.45 \%$ of the respondents (641) were from urban areas. $33.5 \%$ of the respondents are from Lagos State, $33.22 \%$ of the respondents are from FCT, Abuja, and $33.29 \%$ of the respondents are from Kano State.

Ethical approval was obtained from the National Health Research Ethics Committee (NHREC) on September 6, 2017. The research team ensured privacy during the interviews by conducting the in-depth interviews respondents and in reporting of data, coding was employed to anonymize the identity of respondents. Consent was obtained from all participants by explaining the full extent of the survey and having them sign the consent form.

\section{Results}

\subsection{Main Characteristics of Respondents}

A total of 1,442 respondents took part in this research. Median (average) age of respondents was 29 years. Majority of respondents $(66.6 \%)$ were in the age range of 15-34 years. Most of the respondents had some form of formal education. $73.84 \%$ of the respondents were in regular and stable relationship.

\subsection{Description of Results}

The majority of the respondents identified male condom as contraceptives (89.34\%). Very few of the respondents identified Implants $(26.14 \%)$, Tubal ligation $(15.9 \%)$, Vasectomy $(12.83 \%)$ and IUCD $(11.5 \%)$ as types of contraceptives. Older respondents ( 25 to 44 years old) did better than the younger respondents (15 to 24 years) in correctly identifying contraceptives as reversible and non-reversible types.

Table I. Total distribution of respondents from the 3 states of the survey

\begin{tabular}{|c|c|c|c|c|c|c|c|}
\hline S/N & State & Rural & Percent of Rural & Urban & $\begin{array}{c}\text { Percent of } \\
\text { Urban }\end{array}$ & Total & Percent of Total \\
\hline 1 & Lagos & 241 & 30.09 & 242 & 37.75 & 483 & 33.50 \\
\hline 2 & Abuja & 240 & 29.96 & 239 & 37.29 & 479 & 33.22 \\
\hline 3 & Kano & 320 & 39.95 & 160 & 24.96 & 480 & 33.29 \\
\hline \multicolumn{2}{|r|}{ Total } & 801 & & 641 & & 1,442 & \\
\hline
\end{tabular}




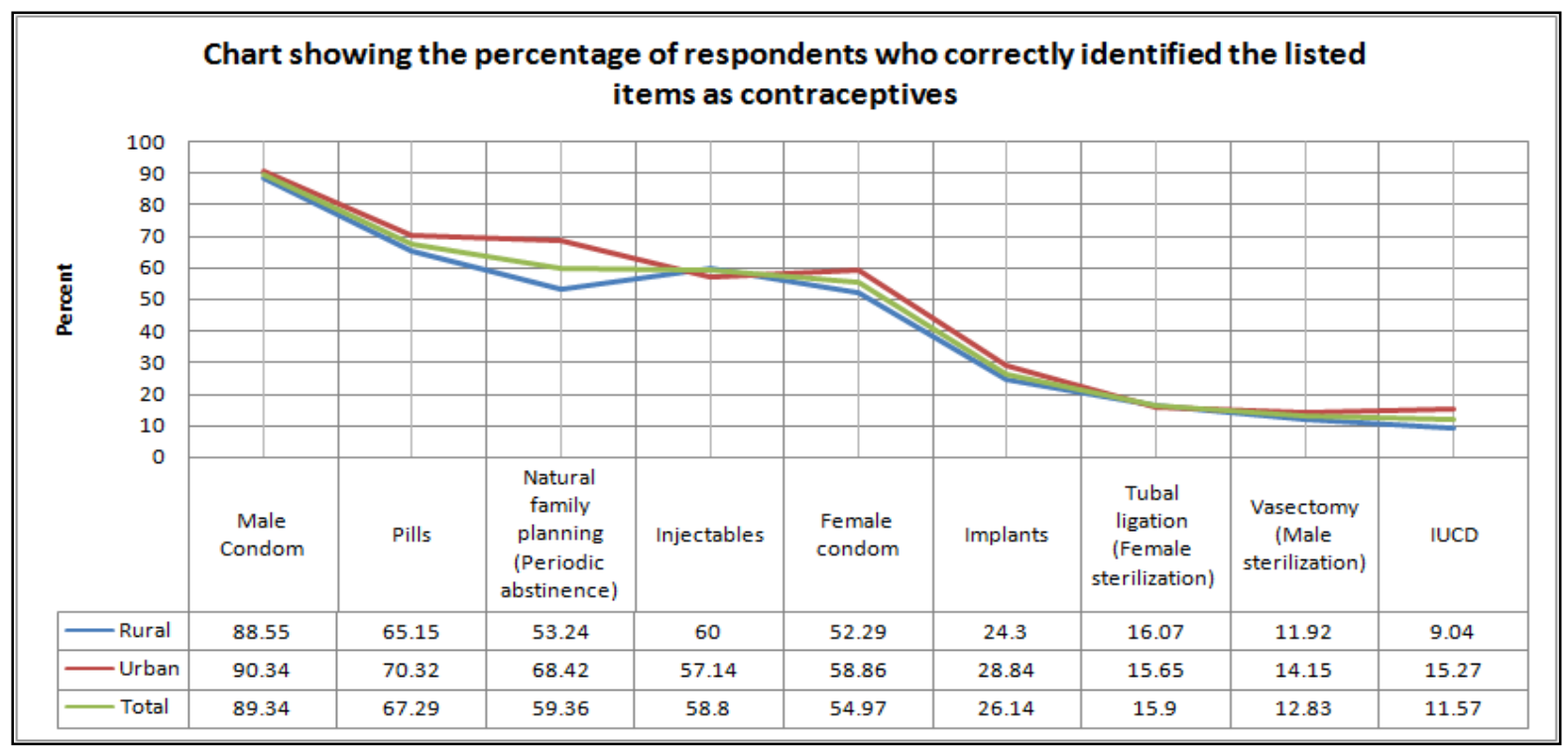

Figure 2. Percentage of respondent who correctly identified listed contraceptives

Table 2. Respondent reasons for contraceptives usage among married couples

\begin{tabular}{|c|l|c|c|c|c|c|c|}
\hline \multirow{2}{*}{ S/N } & $\begin{array}{l}\text { Q5 - In your opinion, what are the common reasons } \\
\text { why MARRIED people use contraceptives? }\end{array}$ & \multicolumn{2}{|c|}{ Rural } & \multicolumn{2}{|c|}{ Urban } & \multicolumn{2}{c|}{ Total } \\
\cline { 5 - 9 } & Frequency & Percent & Frequency & Percent & Frequency & Percent \\
\hline 1 & $\begin{array}{l}\text { Child spacing because of the desire for smaller } \\
\text { family size and adequate provision for the children }\end{array}$ & 405 & 50.56 & 344 & 53.67 & 749 & 51.94 \\
\hline 2 & $\begin{array}{l}\text { Child spacing because of financial burden and } \\
\text { economic constraints }\end{array}$ & 398 & 49.69 & 308 & 48.05 & 706 & 48.96 \\
\hline 3 & Child spacing because of mother's health & 134 & 16.73 & 114 & 17.78 & 248 & 17.20 \\
\hline 4 & Child spacing because of newborn's health & 95 & 11.86 & 94 & 14.66 & 189 & 13.11 \\
\hline 5 & To reduce demand on parents' time & 20 & 2.50 & 42 & 6.55 & 62 & 4.30 \\
\hline 6 & $\begin{array}{l}\text { To free time and resources for parents' further } \\
\text { education and career development }\end{array}$ & 16 & 2.00 & 41 & 6.40 & 57 & 3.95 \\
\hline 7 & $\begin{array}{l}\text { More understanding and advocacy from increased } \\
\text { male roles in parenting }\end{array}$ & 11 & 1.37 & 28 & 4.37 & 39 & 2.70 \\
\hline 8 & Others (Specify) & 77 & 9.61 & 125 & 19.50 & 202 & 14.01 \\
\hline
\end{tabular}

According to the respondents, two top reasons why married people use contraceptives are child spacing because of the desire for smaller family size and adequate provision for the children $(51.94 \%)$ and child spacing because of financial burden and economic constraints (48.96\%).

Similarly, on reasons why unmarried people who are in regular and stable relationships, use contraceptives, majority of them $(51.25 \%)$ chose "Not financially ready and stable for marriage and starting a family" and (27\%) chose other reasons not specified in our options.

$68.85 \%$ of the respondents said they would use reversible contraceptives if they were made available because they like to prevent unwanted pregnancies and also feel they would be easier to use. $31.15 \%$ say they would not use reversible contraceptives if they were made available. Main reason was fear of adverse health risks.

\section{Discussion}

Because the attitude towards contraceptive use can be influenced by relationship status, the research first sought to establish the number of respondents who were in relationships and what kind of relationships they were in. $73.84 \%$ of the respondents said they were in a regular and stable relationship and a little more than half of that number are in a marriage. In all the states surveyed, the most popular contraceptive type the respondents know is male condom followed by injectables. Knowledge of other contraceptives like, IUCD, Tubal Ligation, Vasectomy and implants is very low among the respondents. Again, most 
respondents recognized condoms, both male and female, as reversible contraceptives while, a very small number recognized IUCDs, Vasectomy and Female Ligation as non-reversible contraceptives. When the results of the survey were further broken down by age-range, older respondents ( 25 to 44 years old) did better than the younger respondents (15 to 24 years) in classifying the listed contraceptives as reversible and non-reversible types. It was evident from the findings that a considerable proportion of men had knowledge of family planning methods. This suggests that the male population is neither ignorant of the means of preventing pregnancies nor unwilling to participate in family planning [13].

In the past, family size was a thing of pride, the larger the family, the better. But economic concerns and the need to have the number of children one can cater for have greatly influenced family size. Most of the married respondents (51.94\%) said, "Child spacing because of the desire for smaller family size and adequate provision for the children" was the main reason they use contraception; $51.24 \%$ of the unmarried respondents mentioned, "Not financially ready and stable for marriage and starting a family" as the main reason they use contraception, this was closely followed by the desire to prevent STDs. Most of the respondents said they took responsibility for contraception in their relationships. A further breakdown of these results showed by urban and rural locations shows that there is no significant difference in the distribution of options by total, rural and urban respondents. The most common contraceptive respondents used with their partners were the condom, followed by natural family planning, injectables and pills [14]. Some respondents prefer alternative methods because they are readily available and have been proven effective, traditionally. For some other respondents, according to the quantitative research, alternative methods of contraceptives like ogogoro and herbal medicine from traditional medicine practitioners. are the only form of contraception they are willing to use as they have been tried and tested over the years.

An analysis of the data gathered, revealed that the idea of having several options of reversible male contraceptives is widely accepted. The availability of alternative contraceptive methods influences the acceptance, demand and sustained use of new male contraceptive technologies. $68.85 \%$ of the respondents say they would use reversible male contraceptives, if they were available; $54.27 \%$ of the respondents who were against it, said they would not use reversible male contraceptives because of the fear of adverse health risks. Although they were willing to use other forms of reversible male contraceptives if that was the only one available, most of the respondents said they preferred to use the condom because it was easy to use. While some respondents say that they would prefer the contraceptives to be given out free, $53.51 \%$ showed a willingness to pay for it if it costs less than five hundred naira. Respondents show a general willingness to share the responsibility of contraception in their relationships and in some cases, bear the responsibility.

\section{How much would you be willing to pay for a Reversible Male Contraceptive?}

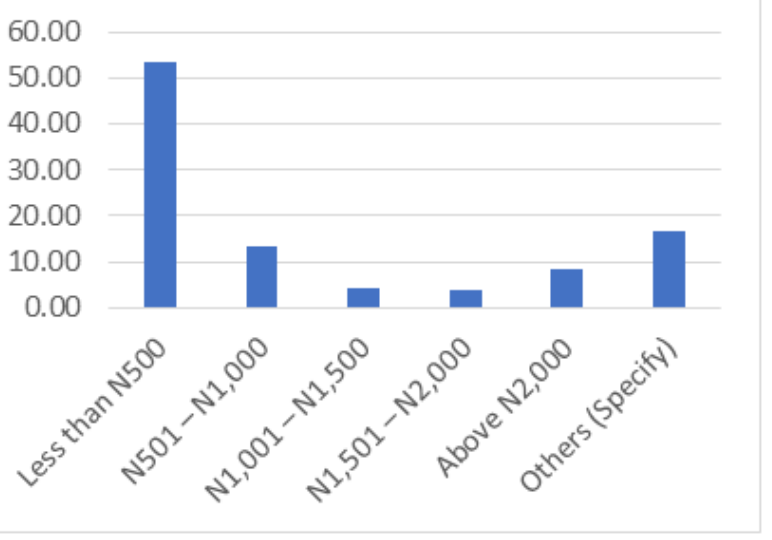

Figure 3. Graph Shows How Much Respondents are willing to Pay for a Reversible Male Contraceptive

Table 3. Percentage distribution of male contraceptive knowledge by age

Q4. Percentage of respondents (valid responses) who correctly identified the following contraceptives as reversible or non-reversible types

\begin{tabular}{|c|l|c|c|c|c|c|c|}
\hline \multirow{2}{*}{ S/N Contraceptives } & \multicolumn{5}{c|}{ Age Range (in Years) } \\
\cline { 3 - 8 } & & $\mathbf{1 5 - 1 9}$ & $\mathbf{2 0 - 2 4}$ & $\mathbf{2 5 - 2 9}$ & $\mathbf{3 0 - 3 4}$ & $\mathbf{3 5 - 3 9}$ & $\mathbf{4 0 - 4 4}$ \\
\hline 1 & Male Condom (Reversible) & 75.49 & 78.97 & 85.53 & 84.62 & 85.06 & 95.04 \\
\hline 2 & Injectables (Reversible) & 36.78 & 50.37 & 55.04 & 55.50 & 65.48 & 66.67 \\
\hline 3 & IUCD (Reversible) & 7.14 & 5.24 & 8.33 & 13.04 & 12.99 & 16.35 \\
\hline 4 & Female Condom (Reversible) & 46.07 & 50.90 & 61.75 & 60.94 & 57.05 & 66.67 \\
\hline 5 & Tubal ligation/Female sterilization (Non-reversible) & 18.29 & 10.86 & 14.01 & 11.93 & 21.77 & 21.43 \\
\hline 6 & Pills (Reversible) & 55.17 & 60.36 & 63.19 & 65.96 & 64.33 & 65.42 \\
\hline 7 & Natural family planning/Periodic abstinence (Reversible) & 43.18 & 47.45 & 59.29 & 63.98 & 63.69 & 73.79 \\
\hline 8 & Vasectomy/Male sterilization (Non-reversible) & 19.05 & 14.07 & 11.61 & 13.74 & 19.73 & 20.39 \\
\hline 9 & Implants (Reversible) & 17.86 & 12.45 & 19.19 & 23.50 & 30.52 & 22.33 \\
\hline
\end{tabular}




\section{Conclusions}

The availability of different types of reversible male contraceptives can be harnessed to create child spacing programs targeted towards population control. This survey has demonstrated that male partners are willing to share responsibility for contraception and pay a maximum of 0 $\mathrm{N} 2,000$ for the uptake of the services. This therefore, is an opportunity for government, international NGOs and development partners to design family planning interventions that have men at the heart of its delivery.

\section{Acknowledgements}

The authors acknowledge Bill and Melinda Gates Foundation who are the funders of this research, Planning, Research and Statistics Department of the Federal Ministry of Health for their collaboration, as well as all respondents who participated in the in-depth interviews, focus group discussions and on-line polls during the research.

\section{REFERENCES}

[1] J. K. Amory. Male contraception. Fertility and sterility, 106(6), 1303-1309. 2016

[2] R.A. Anderson, D. Baird. Male contraception. Endocrine reviews, 23(6):735-762. 2002.

[3] United Nations, Department of Economic and Social Affairs, Population Division (2015). Trends in Contraceptive Use Worldwide 2015 (ST/ESA/SER.A/349).http://www.un.org/ en/development/desa/population/publications/pdf/family/tre ndsContraceptiveUse2015Report.pdf

[4] Ayodamola Owoseye. Contraceptive use among Nigerian women on increase, 2015. https://www.premiumtimesng.co $\mathrm{m} /$ news/headlines/220593-contraceptive-use-among-nigeria n-women-increase.html

[5] H. Youssef. The history of the condom. Journal of the Royal Society of Medicine, 86(4): 226-228. 1993.

[6] E. Dorman, D. Bishai, Demand for male contraception. Expert review of pharmacoeconomics \& outcomes research, 12(5): 605-613, 2012

[7] A. Glasier, R. Anakwe, D. Everington, C. Martin, Z. V. D. Spuy, L. Cheng, P. Ho, R. Anderson. Would women trust their partners to use a male pill? Human Reproduction, 15(3): 646-649, 2000.

[8] C. W. Martin, R.A. Anderson, L. Cheng, P. HO, Z. Van Derspuy, K. Smith, A. Glasier, D. Everington, D.T. Baird. Potential impact of hormonal male contraception: cross-cultural implications for development of novel preparations. Human Reproduction, 15(3): 637-645, 2000.

[9] G. C. Weston, M. L. Schlipalius, M. N. Bhuinneain, B. J. Vollenhoven. Will Australian men use male hormonal contraception? A survey of a postpartum population.
Medical journal of Australia, 176(5): 208-210, 2002

[10] S. Walker. Attitudes to a male contraceptive pill in a group of contraceptive users in the UK. Journal of Men's Health, 8(4): 267-273. 2011.

[11] A. V. Marcell, K. P lowden, S. M. Bowman. Exploring older adolescents' and young adults' attitudes regarding male hormonal contraception: applications for clinical practice. Human Reproduction, 20(11): 3078-3084, 2005.

[12] K. Heinemann, F. Saad, M. Wiesemes, S. White, L. Heinemann. Attitudes toward male fertility control: results of a multinational survey on four continents. Human Reproduction, 20(2): 549-556, 2005.

[13] World Health Organisation. Programming for male involvement in reproductive health services http://whqlibdoc.who.int/hq/2002/WHO_FCH_RHR_02.3. pdf

[14] N. Thummalachetty, S. Mathur, M. Mullinax, K. DeCosta, N. Nakyanjo, T. Lutalo, H. Brahmbhatt, and J. S. Santelli. Contraceptive knowledge, perceptions, and concerns among men in Uganda. 10; 17(1):792. 2017. https://www.ncbi.nlm.nih.gov/pmc/articles/PMC5633881/\# BMC Public Health. 